\title{
Diethyl Ether Production during Catalytic Dehydration of Ethanol over Ru- and Pt- modified H-beta Zeolite Catalysts
}

\author{
Tanutporn Kamsuwan, Piyasan Praserthdam and Bunjerd Jongsomjit* \\ Center of Excellence on Catalysis and Catalytic Reaction Engineering Department of Chemical Engineering, Faculty of Engineering, \\ Chulalongkorn University, Bangkok 10330, THAILAND
}

\begin{abstract}
In the present study, the catalytic dehydration of ethanol over H-beta zeolite (HBZ) catalyst with ruthenium (Ru-HBZ) and platinum (Pt-HBZ) modification was investigated. Upon the reaction temperature between 200 and $400^{\circ} \mathrm{C}$, it revealed that ethanol conversion and ethylene selectivity increased with increasing temperature for both $\mathrm{Ru}$ and $\mathrm{Pt}$ modification. At lower temperature $\left(200\right.$ to $\left.250^{\circ} \mathrm{C}\right)$, diethyl ether (DEE) was the major product. It was found that Ru and Pt modification on HBZ catalyst can result in increased DEE yield at low reaction temperature due to increased ethanol conversion without a significant change in DEE selectivity. By comparing the DEE yield of all catalysts in this study, the Ru-HBZ catalyst apparently exhibited the highest DEE yield (ca. $47 \%$ ) at $250^{\circ} \mathrm{C}$. However, at temperature from 350 to $400^{\circ} \mathrm{C}$, the effect of $\mathrm{Ru}$ and $\mathrm{Pt}$ was less pronounced on ethylene yield. With various characterization techniques, the effects of Ru and Pt modification on HBZ catalyst were elucidated. It revealed that Ru and Pt were present in the highly dispersed forms and well distributed in the catalyst granules. It appeared that the weak acid sites measured by $\mathrm{NH}_{3}$ temperature-programmed desorption technique also decreased with $\mathrm{Ru}$ and $\mathrm{Pt}$ promotion. Thus, the increased DEE yields with the Ru and Pt modification can be attributed to the presence of optimal weak acid sites leading to increased intrinsic activity of the catalysts. It can be concluded that the modification of Ru and Pt on HBZ catalyst can improve the DEE yields by ca. $10 \%$.
\end{abstract}

Key words: ethanol dehydration, H-beta zeolite, diethyl ether, Ruthenium, Platinum

\section{INTRODUCTION}

The catalytic dehydration of ethanol is interesting for production of ethylene and diethyl ether(DEE) from nonpetroleum renewable feedstock due to its cleaner technology. In general, product yields essentially depend on the nature of acid catalyst types used ${ }^{1-3)}$. In fact, catalytic dehydration of ethanol to ethylene over solid acid catalysts requires lower temperature than the conventional thermal cracking $\left(600\right.$ to $\left.1000^{\circ} \mathrm{C}\right)$ of naphtha. This leads to the reduction of energy cost. Besides, ethanol is a green raw material since it is obtained from fermentation of biomass. Basically, ethanol dehydration mainly consists of two competitive pathways as follows ${ }^{1,4)}$;

$$
\begin{array}{cc}
\mathrm{C}_{2} \mathrm{H}_{5} \mathrm{OH} \longrightarrow \mathrm{C}_{2} \mathrm{H}_{4}+\mathrm{H}_{2} \mathrm{O} & +44.9 \mathrm{~kJ} / \mathrm{mol}(1) \\
2 \mathrm{C}_{2} \mathrm{H}_{5} \mathrm{OH} \longrightarrow \mathrm{C}_{2} \mathrm{H}_{5} \mathrm{OC}_{2} \mathrm{H}_{5}+\mathrm{H}_{2} \mathrm{O} & -25.1 \mathrm{~kJ} / \mathrm{mol}(2)
\end{array}
$$

The first reaction(1) is dehydration of ethanol to ethylene (endothermic reaction), while the second one(2) is exothermic reaction to obtain DEE. Thus, ethylene is preferred at high reaction temperature ${ }^{1,3,5)}$, whereas DEE is manly obtained at lower reaction temperature. Ethylene is well known and widely used as a raw material to produce other chemicals ${ }^{6,7)}$, while DEE is a valuable chemical and a green transportation fuel alternative ${ }^{3,8)}$. DEE has been also used as an oxygenated additive for diesel/biodiesel fuels to alleviate $\mathrm{NO}_{\mathrm{x}}$ emission. It is a good ignition improving additive in both diesel and gasoline engines according to its various useful properties such as high volatility and enhancing efficiency for both cetane and octane number in diesel/gasoline engines or as a substitute for liquefied petroleum gas. In addition, DEE is mostly used as a solvent in a number of fine chemistry, fragrance and pharmaceutical chemical processes, and in some processes involved in explosives synthesis ${ }^{3,4,8)}$. In previous years, many researchers have investigated on ethanol dehydration to ethylene,

\footnotetext{
*Correspondence to: Bunjerd Jongsomjit, Center of Excellence on Catalysis and Catalytic Reaction Engineering, Department of Chemical Engineering, Faculty of Engineering, Chulalongkorn University, Bangkok 10330, THAILAND

E-mail: bunjerd.j@chula.ac.th

Accepted August 31, 2016 (received for review June 1, 2016)

Journal of Oleo Science ISSN 1345-8957 print / ISSN 1347-3352 online

http://www.jstage.jst.go.jp/browse/jos/ http://mc.manusriptcentral.com/jjocs
} 


\section{T. Kamsuwan, P. Praserthdam and B. Jongsomjit}

whereas only a few researchers have focused on ethanol dehydration to DEE. As known, DEE is expensive and used in other applications as mentioned above. Currently, DEE is produced as a byproduct of ethanol synthesis by ethylene hydration processes or by dehydration of bioethanol using sulfuric acid or alumina as catalysts ${ }^{4)}$. At present, the beginning to produce DEE is interesting and more challenge in chemical industry. As mentioned before, the production of DEE from ethanol dehydration is favorable at lower temperature. As the result, low ethanol conversion is obtained. Therefore, the design of catalyst to perform high activity at low temperature is very crucial in order to maintain high selectivity of DEE.

Many solid acid catalysts have been used for dehydration of ethanol such as metal oxides, zeolites, supported phosphoric acid, alumina, silica-alumina and heteropolyacid catalysts. The catalytic activity for dehydration of ethanol could be correlated to the number of strong Brønsted acid sites in catalyst ${ }^{3,8-13)}$. In general, alumina, zeolites (alumino-silicate materials), and montmorillonite clays ${ }^{14)}$ have been widely investigated as solid acid catalysts for ethanol dehydration. H-ZSM-5 zeolite has a good performance at lower reaction temperature having higher product yield, but it is easily deactivated by coke formation during the reaction due to its smaller pore size and strong acidic properties $^{12,15)}$. Not only other types of zeolite or modified HZSM-5 as catalysts instead of H-ZSM-5 are preferred to avoid the coke formation during the process of ethanol dehydration $^{9,13,16-19)}$, but it is also necessary to increase the catalytic activity at low temperature. However, there have been some reports on the properties of H-beta zeolite (HBZ) such as microporous zeolite having high surface area, high thermal stability and high acidity used in ethanol dehydration. Moreover, HBZ exhibits larger pore size than H-ZSM-5. Thus, it is favorable to produce hydrocarbon with less coke deposition due to higher diffusivity in the pore ${ }^{20)}$. Promoter is added to improve the catalytic activity in a chemical reaction. In general, promoters have been studied in order to increase the activity of the catalyst and product selectivity. Moreover, chemical promoters including alkali, alkaline earth, halogen group and noble metals such as Rh, $\mathrm{Ru}, \mathrm{Pd}, \mathrm{Pt}, \mathrm{Re}, \mathrm{Au}$, and Ir have been reported to exhibit high catalytic activity ${ }^{13,20-23)}$.

The aim of this work is to investigate the characteristics and catalytic properties of HBZ with Ru and Pt modification, especially to increase the DEE yield at low temperature during ethanol dehydration. The $\mathrm{Ru}$ - and Pt-modified catalysts were prepared by the conventional impregnation method. Then, they were characterized using various techniques. The reaction study of ethanol dehydration was performed using a fixed-bed flow microreactor to measure the ethanol conversion and DEE yield.

\section{EXPERIMENTAL}

\subsection{Materials}

The commercial HBZ used in this study was purchased from Tosoh Corporation. Tetraammineplatinum(II) chloride hydrate (99.99\% Sigma-Aldrich Company Ltd.) and ruthenium (III) nitrosyl nitrate solution (Ru1.5\% Sigma-Aldrich Company Ltd.) were used as Pt and Ru precursors, respectively. Ethanol (99.99\% Merck Company Ltd.) and ultra high purity nitrogen gas[99.99\% Linde(Thailand) Public Company Ltd.] were used for the reaction study.

\subsection{Catalyst preparation}

Besides the HBZ catalyst, other two catalysts were used and prepared from impregnation methods. The HBZ with ruthenium $(\mathrm{Ru})$ and platinum $(\mathrm{Pt})$ modification catalysts were prepared by impregnation method using a proper amount of noble metal precursors to obtain the final catalyst having ca. $0.5 \mathrm{wt} \%$ of noble metal. After impregnation, the catalysts were dried at $110^{\circ} \mathrm{C}$ for $24 \mathrm{~h}$, and then calcined for $2 \mathrm{~h}$ at $550^{\circ} \mathrm{C}$. These catalysts were denoted as HBZ, Ru-HBZ and Pt-HBZ.

\subsection{Catalyst characterization}

All catalysts were characterized by several techniques as follows:

X-ray diffraction (XRD): XRD was performed to determine the bulk crystalline phases of sample. It was conducted using a SIEMENS D-5000 X-ray diffractometer with $\operatorname{CuK}_{\alpha}(\lambda=1.54439 \AA)$. The spectra were scanned at a rate of $2.4^{\circ} \mathrm{min}^{-1}$ in the range of 2 theta degree $=10$ to $90^{\circ}$.

$\mathrm{N}_{2}$ physisorption: Measurement of BET surface area, average pore diameter and pore size distribution were determined by $\mathrm{N}_{2}$ physisorption using a Micromeritics ASAP 2000 automated system.

Scanning electron microscopy (SEM) and energy dispersive X-ray spectroscopy (EDX): SEM and EDX were used to investigate the morphology and elemental distribution of catalysts, respectively using Hitashi mode S-3400N. Micrographs were taken at the accelerating voltage of $30 \mathrm{kV}$ and magnification ranging from 1,000 to 10,000 and the resolution of $3 \mathrm{~nm}$. The SEM was operated using the secondary scattering electron (SE) mode. EDX was performed using Apollo X Silicon Drift Detector Series by EDAX. Before the SEM observation, the sample was conductive to prevent charging by coating with platinum particle under the ion sputtering device.

Temperature-programmed desorption of ammonia $\left(\mathrm{NH}_{3}-\right.$ TPD) : $\mathrm{NH}_{3}$-TPD was performed using Micromeritics chemisorp 2750 pulse chemisorption system to measure the acid properties. In the measurement, $0.1 \mathrm{~g}$ of catalyst was packed in a U-tube glass with $0.03 \mathrm{~g}$ of quartz wool and pretreated at $500^{\circ} \mathrm{C}$ under helium flow for $1 \mathrm{~h}$. Then, the sample was saturated with $15 \%$ of $\mathrm{NH}_{3} / \mathrm{He}$ and the physisorbed ammonia was desorbed under helium gas flow after 
saturation. The sample was heated from $40^{\circ} \mathrm{C}$ to $500^{\circ} \mathrm{C}$ at heating rate of $10^{\circ} \mathrm{C} / \mathrm{min}$.

\subsection{Reaction test}

The catalytic dehydration of ethanol was carried out in a fixed-bed continuous flow microreactor made from a borosilicate glass with an inside diameter of $0.7 \mathrm{~cm}$ and length of $33 \mathrm{~cm}$. In the experiment, $0.01 \mathrm{~g}$ of packed quartz wool and $0.05 \mathrm{~g}$ of catalyst were loaded into the reactor. Then, the catalyst was pretreated in $\operatorname{argon}(60 \mathrm{ml} / \mathrm{min})$ at $200^{\circ} \mathrm{C}$ for $1 \mathrm{~h}$ under atmospheric pressure to remove any moisture on surface of catalyst. The liquid ethanol was vaporized in a flowing of argon by controlled injection with a single syringe pump at a constant flow rate of ethanol $1.45 \mathrm{ml} / \mathrm{h}$ [WHSV $\left.=22.9\left(\mathrm{~g}_{\text {ethanol }} \mathrm{g}_{\mathrm{cat}}{ }^{-1}\right) \mathrm{h}^{-1}\right]$. The ethanol dehydration reaction was carried out at temperature ranging from 200 to $400^{\circ} \mathrm{C}$ by feeding the vaporized ethanol into the reactor. The products were analyzed by a Shimadzu GC8A gas chromatograph with flame ionization detector(FID) using capillary column (DB-5). Nitrogen (pressure of $260 \mathrm{kPa}$ ) was used as carrier gas in GC using the temperature of injector and detector at $150^{\circ} \mathrm{C}$.

\section{RESULTS AND DISCUSSION}

\subsection{Characteristics}

The XRD patterns for HBZ and Ru- and Pt-modified HBZ catalysts are shown in Fig. 1. They confirmed that the structure of HBZ did not change with Ru and Pt modification. However, the XRD peaks of both Ru and Pt were not detected due to their highly dispersed forms ${ }^{18-20)}$ indicating the similar XRD patterns for all catalysts. The characteristic sharp peaks of HBZ catalyst are present at $2 \theta 14.6$ and $22.4^{\circ 20,24)}$. After the modification of $\mathrm{Ru}$ and Pt into HBZ to obtain the Ru-HBZ and Pt-HBZ catalyst, it was ap-

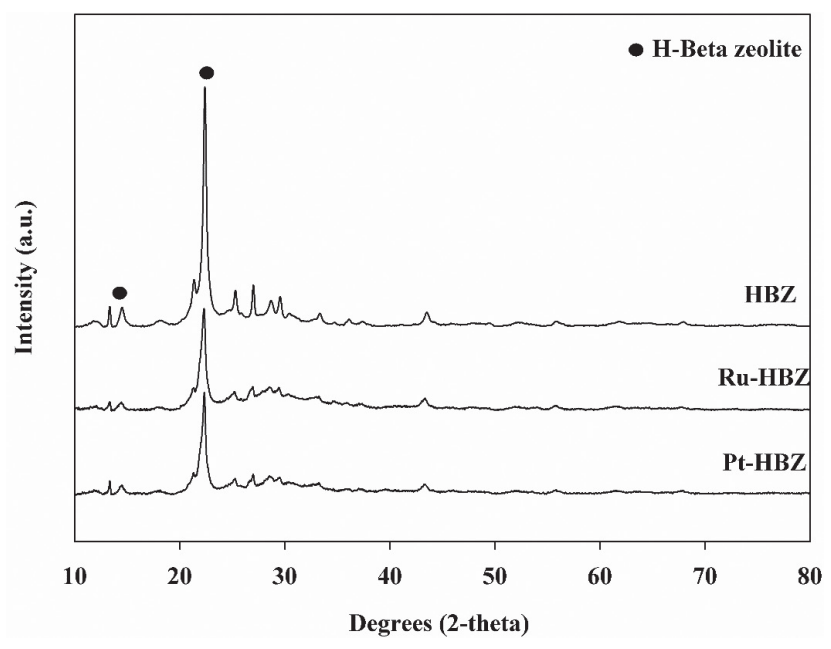

Fig. 1 XRD patterns of all catalysts. peared that the intensity of characteristic peaks (14.6 and $22.4^{\circ}$ ) for HBZ slightly decreased suggesting that the lower crystallinity of modified HBZ catalysts was obtained.

The BET surface area $\left(\mathrm{S}_{\mathrm{BET}}\right)$ and pore size diameter of catalysts were also determined by $\mathrm{N}_{2}$ physisorption and the results are shown in Table 1. The surface areas of all catalysts were ca. 520 to $560 \mathrm{~m}^{2} / \mathrm{g}$. The HBZ catalyst exhibited the lowest surface area of $522 \mathrm{~m}^{2} / \mathrm{g}$. It revealed that after modification of Ru and Pt into HBZ, both surface area and pore size diameter of HBZ were increased. This is probably due to both $\mathrm{Ru}$ and Pt increase the surface area by themselves without significant change in pore structure of HBZ. This can be confirmed the pore structures by the $\mathrm{N}_{2}$ adsorption-desorption isotherms for all catalysts as shown in Fig. 2. It indicates that all catalysts exhibited the microporous structure according to Type I as classified by IUPAC (International Union of Pure and Applied Chemistry). Only a small hysteresis loop of the Ru- and Pt-modified HBZ was observed suggesting that only a small portion of mesopores existed in Ru-HBZ and Pt-HBZ catalysts, which is mainly caused by the aggregation of small crystals leading to the presence of intercrystalline porosity ${ }^{15}$. The pore size distributions of all catalysts are shown in Fig. 3, which is corresponding to the pore structure as also mentioned in Fig. 2. However, pore size distribution (Fig. 3) of all catalysts was found to be only slightly different. It can be seen that the modified catalysts show a narrow pore size distribution

Table 1 BET surface area and pore size diameter.

\begin{tabular}{ccc}
\hline Catalyst & $\begin{array}{c}\text { Pore size diameter } \\
(\mathrm{nm})\end{array}$ & $\begin{array}{c}\text { BET Surface Area } \\
\mathrm{S}_{\mathrm{BET}}\left(\mathrm{m}^{2} / \mathrm{g}\right)\end{array}$ \\
\hline HBZ & 2.2 & 522 \\
Ru-HBZ & 3.7 & 541 \\
Pt-HBZ & 3.8 & 561 \\
\hline
\end{tabular}

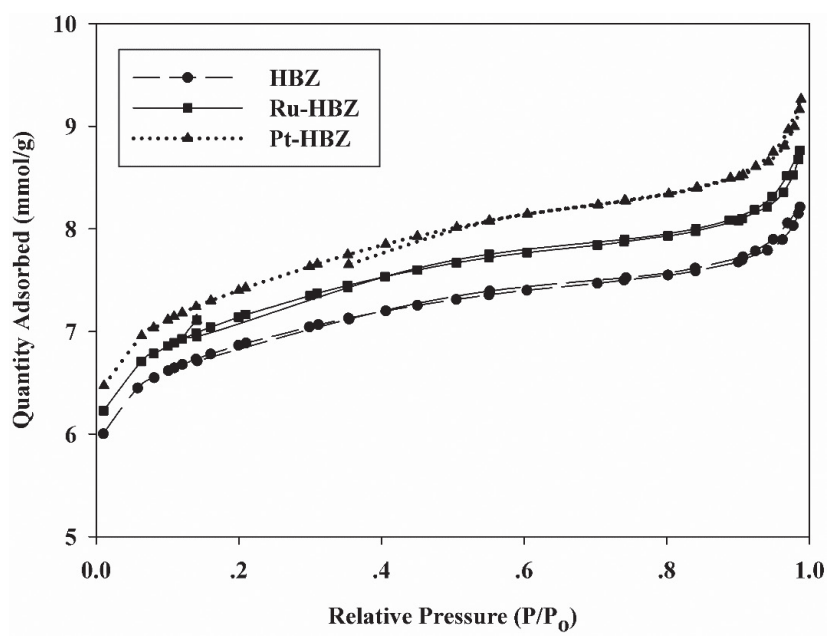

Fig. 2 The $\mathrm{N}_{2}$ adsorption-desorption isotherms of all catalysts. 


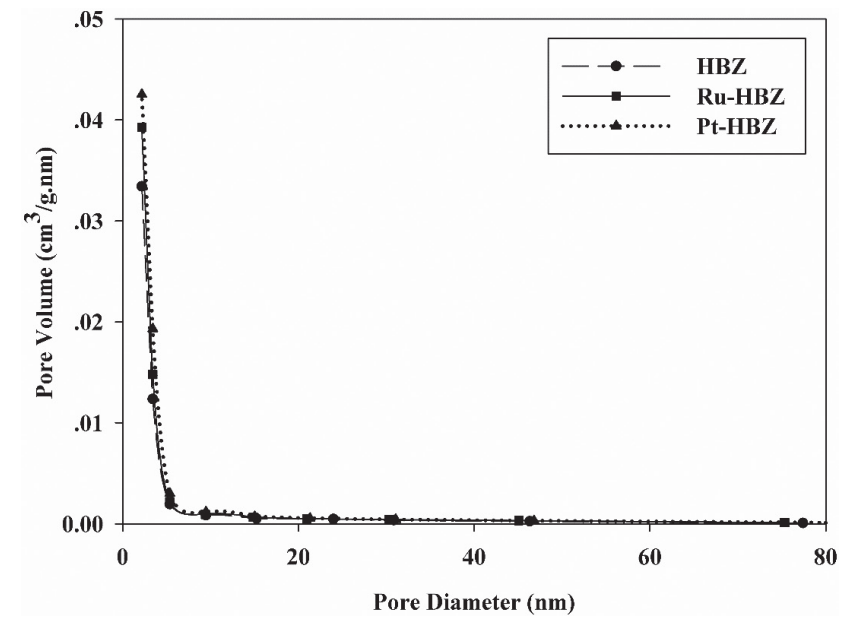

Fig. 3 Pore size distribution of all catalysts.

range of 3-4 nm, confirming the presence of little mesopores nature.

The morphologies of the HBZ and, Ru- and Pt-modified HBZ catalysts were determined by scanning electron microscopy (SEM) as shown in Fig. 4. It can be observed that morphologies of all catalysts were similar illustrating the spheroidal shape of catalysts. The EDX analysis was also performed to quantitatively measure the amounts of ele- mental composition on the catalyst surface. The detection limit of EDX is about 5 microns from the outer surface, which cannot detect element in the bulk of catalyst. The results of quantitatively elemental distribution in all catalysts are shown in Table 2. The amounts of $\mathrm{Ru}$ and $\mathrm{Pt}$ on surface were of 0.33 and $0.65 \mathrm{wt} \%$ on the $\mathrm{Ru}$ - and Pt-modified HBZ catalyst, respectively. From EDX mapping, it indicated that Pt was mostly located on the outer surface of HBZ, whereas Ru was better distributed inside the catalyst granule as seen in Fig. 5 revealing the elemental distribution by EDX mapping in cross-sectional area of modified HBZ catalysts.

The acidity of catalysts was determined by $\mathrm{NH}_{3}$-TPD technique. The $\mathrm{NH}_{3}$-TPD profiles of all catalysts are shown in Fig. 6. The surface acidity and strength of acid site are important factor to determine the catalytic activity of ethanol dehydration ${ }^{15,25,26)}$. It revealed that all $\mathrm{NH}_{3}-\mathrm{TPD}$ profiles were similar consisting of two groups of desorption peaks. The first desorption peaks at low temperature (below $250^{\circ} \mathrm{C}$ ) are assigned to weak acid sites and those above $400^{\circ} \mathrm{C}$ are strong acid sites ${ }^{7,13,27)}$. The number of acid sites on catalyst can be calculated by integration of desorption peak area of ammonia according to the Gauss curve fitting method. The amount of acidity of catalysts is also displayed in Table 3. It was found that amounts of weak
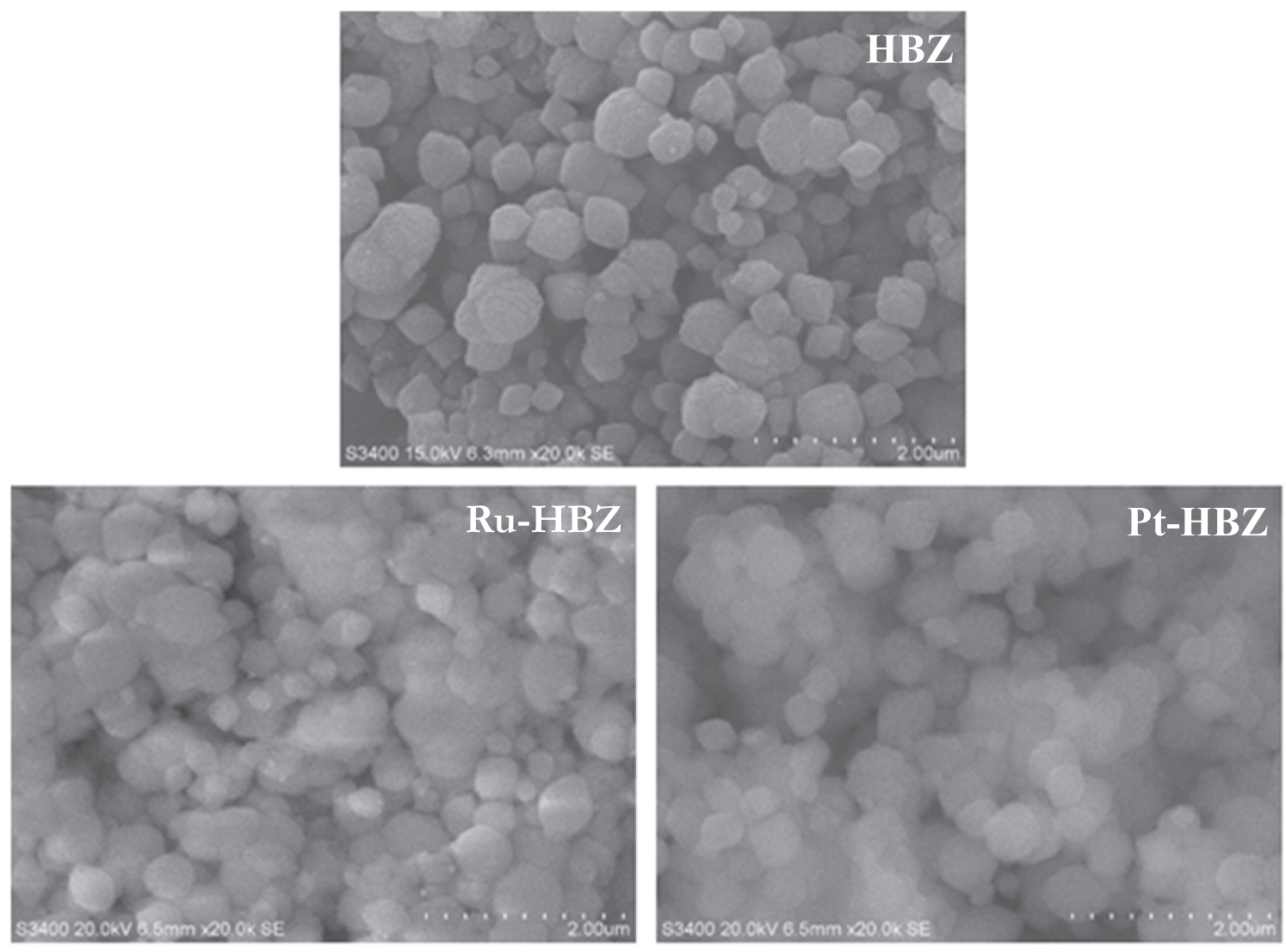

Fig. 4 SEM images of all catalysts. 
Catalytic dehydration of ethanol

Table 2 Elemental distribution obtained from EDX.

\begin{tabular}{cccccccccc}
\hline & \multicolumn{1}{c}{ Element } \\
\cline { 2 - 10 } Catalyst & \multicolumn{3}{c}{ \% Weight } & \multicolumn{7}{c}{ \% Atom } \\
\cline { 2 - 10 } & $\mathrm{Al}$ & $\mathrm{Si}$ & $\mathrm{O}$ & $\begin{array}{c}\text { Noble } \\
\text { metal }\end{array}$ & $\mathrm{Si} / \mathrm{Al}$ & $\mathrm{Al}$ & $\mathrm{Si}$ & $\mathrm{O}$ & $\begin{array}{c}\text { Noble } \\
\text { metal }\end{array}$ \\
\hline HBZ & 2.88 & 59.99 & 37.13 & - & 20.83 & 2.34 & 46.81 & 37.13 & - \\
Ru-HBZ & 2.61 & 48.14 & 48.93 & 0.33 & 18.44 & 1.98 & 35.18 & 62.77 & 0.07 \\
Pt-HBZ & 3.00 & 45.37 & 50.98 & 0.65 & 15.12 & 2.26 & 32.86 & 64.81 & 0.07 \\
\hline
\end{tabular}
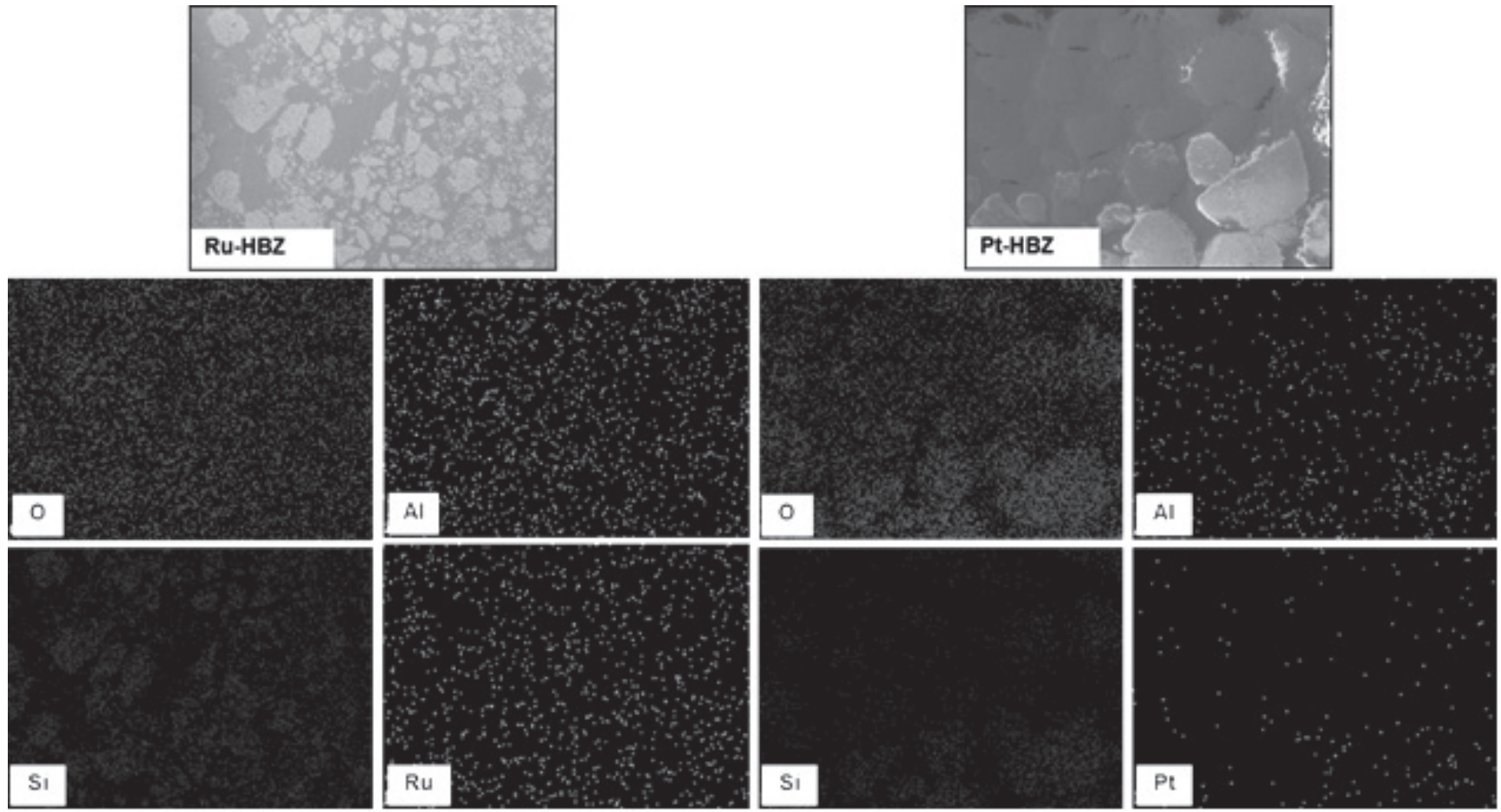

Fig. 5 Cross-sectional elemental distribution by EDX mapping for all Ru-HBZ and Pt-HBZ catalysts.

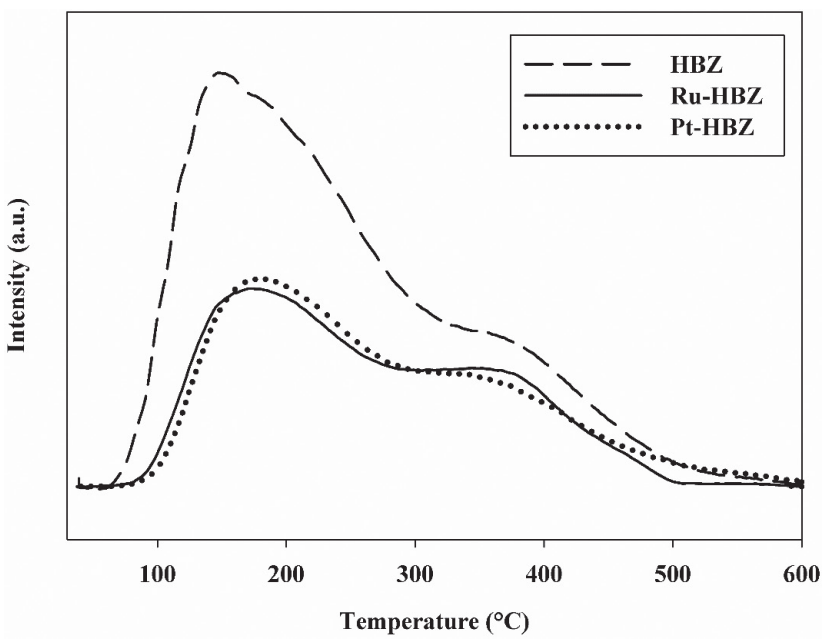

Fig. $6 \mathrm{NH}_{3}$-TPD profile of all catalysts.
Table 3 Acidity from $\mathrm{NH}_{3}-\mathrm{TPD}$.

\begin{tabular}{cccc}
\hline & \multicolumn{2}{c}{$\begin{array}{c}\mathrm{NH}_{3} \text { desorption } \\
(\mu \mathrm{mol} \mathrm{NH} / \text { g cat. })\end{array}$} & $\begin{array}{c}\text { Total acidity } \\
\left(\mu \mathrm{mol} \mathrm{NH} \mathrm{N}_{3} / \text { gcat. }\right)\end{array}$ \\
\cline { 2 - 3 } Samples & Weak & $\begin{array}{c}\text { Medium } \\
\text { to strong }\end{array}$ & \\
\hline HBZ & 844.8 & 672.5 & 1517 \\
Ru-HBZ & 695.0 & 624.6 & 1320 \\
Pt-HBZ & 756.4 & 685.8 & 1442 \\
\hline
\end{tabular}

acid and total acid sites tended to decrease in the order of HBZ $>$ Pt-HBZ $>$ Ru-HBZ, whereas the amount of strong acid sites of all catalyst was slightly different. The amount of strong acid site of Ru-HBZ is slightly lower than HBZ and Pt-HBZ. This indicates that the modification of $\mathrm{Ru}$ and Pt on HBZ can alter the acidity of catalysts. In addition, the slight difference in weak, moderate to strong and total acidity of all catalysts is likely due to significant change in 
$\mathrm{Si} / \mathrm{Al}$ ratios $^{15,28)}$.

\subsection{Reaction study}

The catalytic properties of all catalysts for ethanol dehydration at temperature ranging from 200 to $400^{\circ} \mathrm{C}$ in terms of ethanol conversion are presented in Fig. 7. It was found that all catalysts exhibited the similar catalytic behavior, where the conversion of all catalysts increased with increasing the reaction temperature. At $400^{\circ} \mathrm{C}$, all catalysts exhibited the highest ethanol conversion. The conversion of Ru- and Pt-modified HBZ catalysts enhanced the conversion of ethanol, especially at temperature between 250 and $300^{\circ} \mathrm{C}$. However, the effect of $\mathrm{Ru}$ and $\mathrm{Pt}$ modification was less pronounced on ethanol conversion at high temperature $\left(>300^{\circ} \mathrm{C}\right)$. The product selectivity for all catalysts is shown in Table 4. For ethylene selectivity, it was found that the selectivity of ethylene increased with increasing the reaction temperature. The modification of $\mathrm{Ru}$ and $\mathrm{Pt}$ can result in increased ethylene selectivity only at $300^{\circ} \mathrm{C}$. Meanwhile, the results of DEE selectivity for all catalysts indicate that they apparently decreased with increased temperature. At $250^{\circ} \mathrm{C}$, Ru modification resulted in slightly increased DEE selectivity. Although all catalysts exhibit

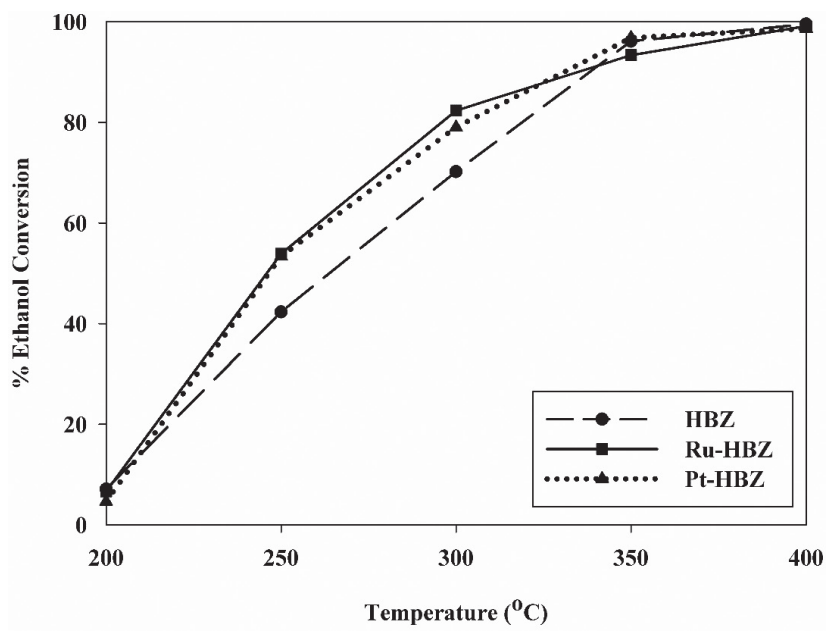

Fig. 7 Ethanol conversion of all catalysts at different temperatures. the highest DEE selectivity at $200^{\circ} \mathrm{C}$, ethanol conversion at this temperature is the lowest. Therefore, it is necessary to consider the DEE yield obtained (product of ethanol conversion and DEE selectivity) for each temperature.

The yields of ethylene and DEE are shown in Figs. 8 and 9. Consider the yield of ethylene, it can be observed that the $\mathrm{Ru}$ and $\mathrm{Pt}$ modification can significantly increase the ethylene yield from ca. $46 \%$ to $55 \%$ (with Pt) or $60 \%$ (with $\mathrm{Ru}$ ) at $300^{\circ} \mathrm{C}$. However, at temperature higher than $300^{\circ} \mathrm{C}$, it was found that the effect of $\mathrm{Ru}$ and $\mathrm{Pt}$ modification was less pronounced due to more kinetics control. The DEE yields for all catalysts are illustrated in Fig. 9. It reveals that the highest DEE yields for all catalysts were obtained at $250^{\circ} \mathrm{C}$. Thus, this temperature is the most suitable temperature for DEE production. At this temperature, both $\mathrm{Ru}$ and Pt modifications can increase the DEE yield by ca. $10 \%$. In all cases, the increase in DEE yield is caused by an increase in catalytic activity with $\mathrm{Ru}$ and $\mathrm{Pt}$ as chemical promoters without significant change in selectivity of DEE. In can explain that the Ru- and Pt-modified HBZ catalysts may be able to enhance possibility for reactants to contact and react, leading to increased catalytic activity for ethanol dehydration. This is corresponding to the ethanol conver-

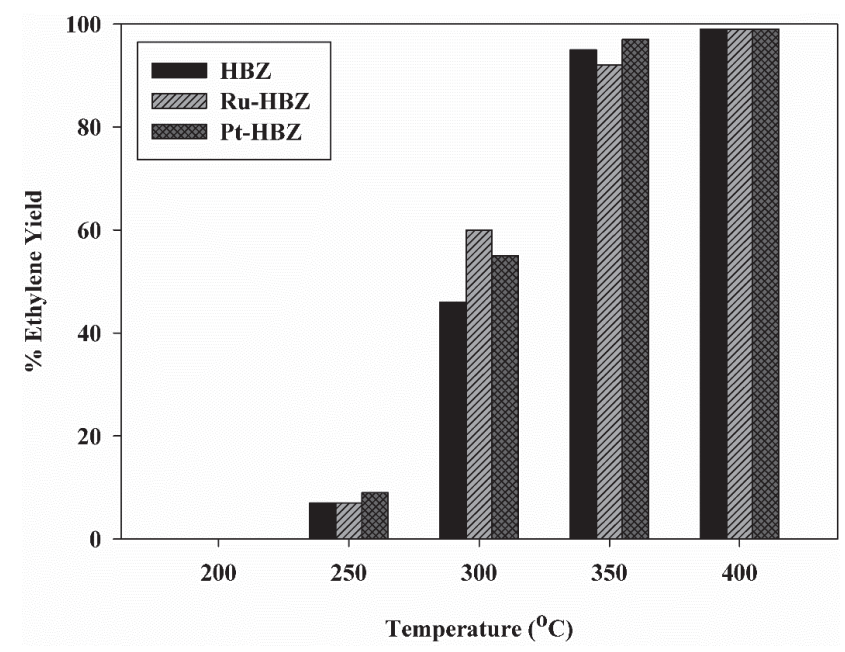

Fig. 8 Ethylene yield of all catalysts at different temperatures.

Table $4 \%$ Selectivity of products.

\begin{tabular}{ccrrrrr}
\hline \multirow{2}{*}{ Catalyst } & Products selectivity & \multicolumn{5}{c}{ Temperature $\left({ }^{\circ} \mathrm{C}\right)$} \\
\cline { 3 - 7 } & $(\%)$ & 200 & 250 & 300 & 350 & \multicolumn{1}{c}{400} \\
\hline \multirow{2}{*}{$\mathrm{HBZ}$} & Ethylene & 0.5 & 16.5 & 65.0 & 98.7 & 99.9 \\
& DEE & 99.5 & 83.5 & 35.0 & 1.2 & 0.0 \\
\multirow{3}{*}{$\mathrm{Ru}-\mathrm{HBZ}$} & Ethylene & 1.0 & 13.3 & 73.5 & 98.3 & 100.0 \\
& DEE & 99.0 & 86.7 & 26.5 & 1.7 & 0.0 \\
\multirow{2}{*}{ Pt-HBZ } & Ethylene & 0.8 & 16.5 & 69.8 & 99.8 & 100.0 \\
& DEE & 99.2 & 83.5 & 30.2 & 0.2 & 0.0 \\
\hline
\end{tabular}




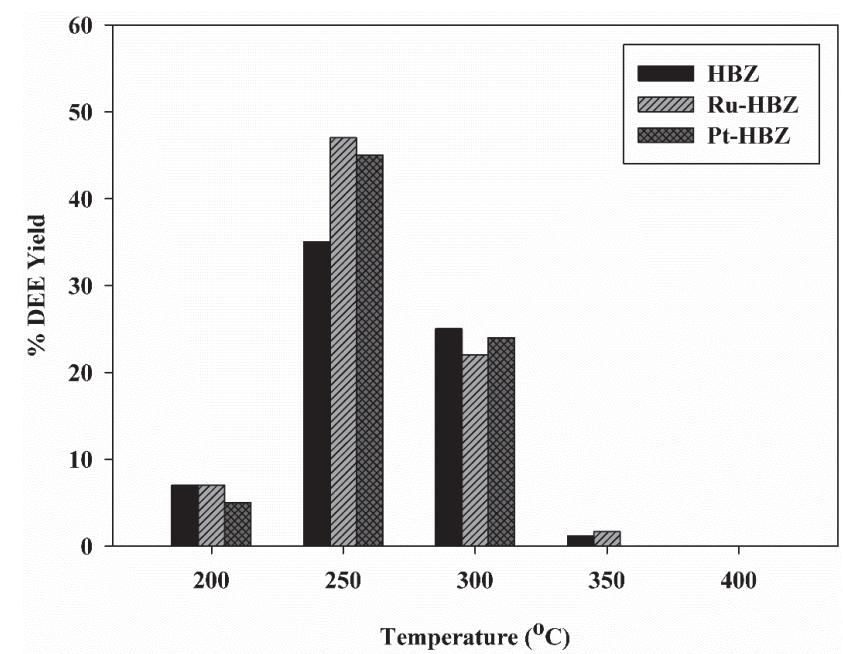

Fig. 9 DEE yield of all catalysts at different temperatures.

sion of the modified catalysts that increases at low reaction temperature. Previous results also indicated that the relatively high dehydration activities for catalysts containing noble metal at lower reaction temperatures is in good agreement with this study. The similar phenomenon is also applied for the increase in ethylene yield at $300^{\circ} \mathrm{C}$ with $\mathrm{Ru}$ and Pt modification. It should be noted that acidity decreased with $\mathrm{Ru}$ and $\mathrm{Pt}$ modification suggesting the increase in intrinsic activity with chemical promoter.

Based on our present study, the high DEE yield (47\%) during catalytic ethanol dehydration with $\mathrm{Ru}-\mathrm{HBZ}$ catalyst was obtained. In order to compare the result with other researches, the DEE yields from ethanol dehydration with various catalysts are summarized in Table 5. Previous reports also indicated that the chemical promoter is necessary for improvement of the DEE yield due to increased catalytic activity $^{8,11,23)}$. Therefore, the modified HBZ is suitable to be applied for the ethanol dehydration to produce DEE. Based on data, it can be presumable that the modification of zeolite-based catalysts with $\mathrm{Ru}$ and $\mathrm{Pt}$ is promising to enhance the production of DEE at low temperature.

\section{CONCLUSION}

The modification of HBZ with $\mathrm{Ru}$ and Pt is promising to enhance the product yields at low temperature. In case of ethylene yield, the effect of Ru and Pt modification on HBZ catalyst was more pronounced at temperature of $300^{\circ} \mathrm{C}$, whereas at higher temperature the kinetics control is more dominant. In order to increase the DEE yield, the ethanol dehydration must be operated at low temperature to maintain high selectivity of DEE. Therefore, Ru and Pt modifications are necessary to increase the DEE yield because they can act as a chemical promoter. Based on this study, the highest DEE yield (47\%) can be obtained with the Ru-HBZ catalyst at $250^{\circ} \mathrm{C}$.

\section{Acknowledgement}

The authors thank the Thailand Research Fund and Grant for International Research Integration: Chula Research Scholar, Ratchadaphiseksomphot Endowment Fund for financial support of this project.

Table 5 Comparison of various catalysts for DEE yield and catalytic ability.

\begin{tabular}{|c|c|c|c|c|}
\hline Catalyst & $\begin{array}{c}\text { Reaction } \\
\text { temperature } \\
\left({ }^{\circ} \mathrm{C}\right)\end{array}$ & $\begin{array}{c}\text { Ethanol } \\
\text { conversion } \\
(\%)\end{array}$ & $\begin{array}{l}\text { DEE yield } \\
(\%)\end{array}$ & Ref. \\
\hline $\mathrm{HBZ}$ & 250 & 66 & 35 & This work \\
\hline $\mathrm{Ru}-\mathrm{HBZ}$ & 250 & 73 & 47 & This work \\
\hline Pt-HBZ & 250 & 70 & 45 & This work \\
\hline $\mathrm{ZrO}_{2}$ & $250-350$ & $0-45$ & $0-3$ & (11) \\
\hline $\mathrm{TiO}_{2}$ & $200-350$ & $0-80$ & $1-47$ & (11) \\
\hline $\mathrm{WO}_{3} / \mathrm{ZrO}_{2}$ & $150-250$ & $1-54$ & $1-42$ & (11) \\
\hline $\mathrm{WO}_{3} / \mathrm{TiO}_{2}(\mathrm{H})$ & $150-250$ & $12-89$ & $10-68$ & (11) \\
\hline 2\%PHZSM-5 & $200-240$ & $69-96$ & $23-66$ & (18) \\
\hline $0.5 \%$ LaHZSM-5 & 200 & 86 & 29 & (18) \\
\hline H-ZSM-5 & 300 & 90 & 14 & (19) \\
\hline 20HP-ZSM-5 & $250-450$ & $25-100$ & $0-24$ & (19) \\
\hline
\end{tabular}




\section{T. Kamsuwan, P. Praserthdam and B. Jongsomjit}

\section{References}

1) Chen, Y.; Wu, Y.; Tao, L.; Dai, B.; Yang, M.; Chen, Z.; Zhu, X. Dehydration reaction of bio-ethanol to ethylene over modified SAPO catalysts. J. Ind. Eng. Chem. 16, 717-722 (2010).

2) Phung, T.K.; Lagazzo, A.; Rivero Crespo, M.Á.; Sánchez Escribano, V.; Busca, G. A study of commercial transition aluminas and of their catalytic activity in the dehydration of ethanol. J. Catal. 311, 102-113(2014).

3) Alharbi, W.; Brown, E.; Kozhevnikova, E.F.; Kozhevnikov, I.V. Dehydration of ethanol over heteropoly acid catalysts in the gas phase. J. Catal. 319, 174-181 (2014).

4) Phung, T.K.; Busca, G. Diethyl ether cracking and ethanol dehydration: Acid catalysis and reaction paths. Chem. Eng. J. 272, 92-101(2015).

5) Fan, D.; Dai, D.-J.; Wu, H.-S. Ethylene Formation by Catalytic Dehydration of Ethanol with Industrial Considerations. Materials 6, 101-115(2012).

6) Kagyrmanova, A.P.; Chumachenko, V.A.; Korotkikh, V.N.; Kashkin, V.N.; Noskov, A.S. Catalytic dehydration of bioethanol to ethylene: Pilot-scale studies and process simulation. Chem. Eng. J. 176-177, 188-194 (2011).

7) Bokade, V.V.; Yadav, G.D. Heteropolyacid supported on montmorillonite catalyst for dehydration of dilute bioethanol. Appl. Clay Sci. 53, 263-271 (2011).

8) Rahmanian, A.; Ghaziaskar, H.S. Continuous dehydration of ethanol to diethyl ether over aluminum phosphate-hydroxyapatite catalyst under sub and supercritical condition. J. Supercrit. Fluids 78, 34-41 (2013).

9) Duan, C.; Zhang, X.; Zhou, R.; Hua, Y.; Zhang, L.; Chen, J. Comparative studies of ethanol to propylene over HZSM-5/SAPO-34 catalysts prepared by hydrothermal synthesis and physical mixture. Fuel Process. Technol. 108, 31-40 (2013).

10) Matachowski, L.; Zimowska, M.; Mucha, D.; Machej, T. Ecofriendly production of ethylene by dehydration of ethanol over $\mathrm{Ag}_{3} \mathrm{PW}_{12} \mathrm{O}_{40}$ salt in nitrogen and air atmospheres. Appl. Catal. B 123-124, 448-456 (2012).

11) Phung, T.K.; Proietti Hernández, L.; Busca, G., Conversion of ethanol over transition metal oxide catalysts: Effect of tungsta addition on catalytic behaviour of titania and zirconia. Appl. Catal. A 489, 180-187 (2015).

12) Phung, T.K.; Proietti Hernández, L.; Lagazzo, A.; Busca, G. Dehydration of ethanol over zeolites, silica alumina and alumina: Lewis acidity, Brønsted acidity and confinement effects. Appl. Catal. A 493, 77-89(2015).

13) Han, Y.; Lu, C.; Xu, D.; Zhang, Y.; Hu, Y.; Huang, H. Molybdenum oxide modified HZSM-5 catalyst: Surface acidity and catalytic performance for the dehydration of aqueous ethanol. Appl. Catal. A 396, 8-13(2011).
14）Krutpijit, C.; Jongsomjit, B., Catalytic Ethanol Dehydration over Different Acid-activated Montmorillonite Clays. J. Oleo Sci. 65, 347-355(2016).

15) Sheng, Q.; Ling, K.; Li, Z.; Zhao, L. Effect of steam treatment on catalytic performance of HZSM-5 catalyst for ethanol dehydration to ethylene. Fuel Process. Technol. 110, 73-78(110).

16) Furumoto, Y.; Tsunoji, N.; Ide, Y.; Sadakane, M.; Sano, T. Conversion of ethanol to propylene over HZSM-5 (Ga) co-modified with lanthanum and phosphorous. Appl. Catal. A 417-418, 137-144(2012).

17) Wang, F.; Luo, M.; Xiao, W.; Cheng, X.; Long, Y. Coking behavior of a submicron MFI catalyst during ethanol dehydration to ethylene in a pilot-scale fixed-bed reactor. Appl. Catal. A 393, 161-170(2011).

18) Zhan, N.; Hu, Y.; Li, H.; Yu, D.; Han, Y.; Huang, H. Lanthanum-phosphorous modified HZSM-5 catalysts in dehydration of ethanol to ethylene: A comparative analysis. Catal. Commun. 11, 633-637 (2010) .

19) Ramesh, K.; Hui, L.; Han, Y.; Borgna, A. Structure and reactivity of phosphorous modified H-ZSM- 5 catalysts for ethanol dehydration. Catal. Commun. 10, 567-571 (2009).

20) Sujeerakulkai, S.; Jitkarnka, S. Bio-based hydrocarbons and oxygenates from catalytic bio-ethanol dehydration: comparison between gallium and germanium oxides as promoters on HBeta zeolites with various silica to alumina ratios. J. Clean. Prod. 111, 51-61 (2016).

21) Wan Abu Bakar, W.A.; Ali, R.; Mohammad, N.S. The effect of noble metals on catalytic methanation reaction over supported Mn/Ni oxide based catalysts. Arab. $J$. Chem. 8, 632-643(2015).

22) Yuan, C.; Liu, H.; Zhang, Z.; Lu, H.; Zhu, Q.; Chen, Y. Alkali-metal-modified ZSM-5 zeolites for improvement of catalytic dehydration of lactic acid to acrylic acid. Chin. J. Catal. 36, 1861-1866 (2015).

23) Chinniyomphanich, U.; Wongwanichsin, P.; Jitkarnka, S. $\mathrm{Sn}_{\mathrm{x}} \mathrm{O}_{\mathrm{y}} / \mathrm{SAPO}-34$ as catalysts for catalytic dehydration of bio-ethanol: impacts of oxidation state, interaction, and loading amount. J. Clean. Prod. 111, 25-33 (2016).

24） Jansen, J.C.; Creyghtonb, E.J.; Njoa, S.L.; van Koningsvelda, H.; van Bekkum, H. On the remarkable behaviour of zeolite Beta in acid catalysis. Catal. Today 38, 205-212 (1997).

25) Phung, T.K.; Busca, G. Ethanol dehydration on silicaaluminas: Active sites and ethylene/diethyl ether selectivities. Catal. Commun. 68, 110-115(2015).

26) Xin, H.; Li, X.; Fang, Y.; Yi, X.; Hu, W.; Chu, Y.; Zhang, F.; Zheng, A.; Zhang, H.; Li, X. Catalytic dehydration of ethanol over post-treated ZSM-5 zeolites. J. Catal. 312, 204-215(2014).

27) Nguyena, T.T.N.; Ruauxb, V.; Massin, L.; Lorentza, C.; 
Afanasieva, P.; Maugéb, F.; Bellière-Bacac, V.; P.Reyc; Millet, J.M.M. Synthesis, characterization and study of lanthanum phosphates as light alcohols dehydration catalysts. Appl. Catal. B 166-167, 432-444(2015).

28) Hajimirzaee, S.; Ainte, M.; Soltani, B.; Behbahani, R.M.;
Leeke, G.A.; Wood, J. Dehydration of methanol to light olefins upon zeolite/alumina catalysts: Effect of reaction conditions, catalyst support and zeolite modification. Chem. Eng. Res. Des. 93, 541-553(2015). 